\title{
Aplicación de la Convención de Nueva York por las cortes Lationamericanas")
}

\section{Application of New York Convention by Latin American courts}

\author{
Fernando Cantuarias Salaverry ${ }^{(* *)}$ \\ Universidad del Pacífico \\ Jose Luis Repetto Deville ${ }^{(* *)}$ \\ Universidad del Pacífico
}

\begin{abstract}
Resumen: A través de este artículo, los autores comentan la aplicación de la Convención sobre el Reconocimiento y la Ejecución de Sentencias Arbitrales Extranjeras, aprobada en Nueva York el 10 de junio de 1958, a través de la revisión de la jurisprudencia más relevante de las principales jurisdicciones en materia arbitral de América Latina. El siguiente artículo aporta una revisión de las diferentes causales que puede utilizar una parte para oponerse al reconocimiento de un laudo evidenciándose los criterios que emplean las cortes para amparar o denegar el reconocimiento de un laudo extranjero.
\end{abstract}

Palabras clave: Arbitraje - Reconocimiento de Laudos - Exequatur Jurisprudencia - Latinoamérica - Convención de Nueva York

Abstract: Through this paper, the authors comment on the application of the Convention on the Recognition and Enforcement of Foreign Arbitral Awards,

(*) Nota del editor: Este artículo fue recibido 10 de noviembre de 2017 y su publicación fue aprobada el 30 de noviembre de 2017.

${ }^{* *}$ Abogado por la Pontificia Universidad Católica del Perú y Master en Derecho (LL.M.) por la Universidad de Yale. Decano de la Facultad de Derecho de la Universidad del Pacífico. Profesor de Arbitraje Comercial y Arbitraje de las Inversiones. Árbitro nacional e internacional. Miembro del Board of Reporters del Institute of Transnacional Arbitration (ITA), del Grupo Latinoamericano de Arbitraje de la Cámara de Comercio Internacional $(\mathrm{CCl})$, de la Asociación Americana de Derecho Internacional Privado (ASADIP), del Comité Editor de la Revista Peruana de Arbitraje, de la Association for International Arbitration (AIA), de la Asociación Latinoamericana de Arbitraje y del Comité Argentino de Arbitraje Nacional y Transnacional (CARAT). Miembro de la lista de árbitros de los principales Centros de Arbitraje del Perú y del Energy Arbitrators' list. Coautor de la Ley de Arbitraje peruana de 2008. Moderador del ITA FORO DE ARBITRAJE LATINOAMERICANO (ITAFOR). Correo electrónico: fccantuar@gmail.com.

${ }^{* \star *}$ Abogado por la Universidad del Pacífico. Asociado del Área de Arbitraje de Miranda \& Amado. Jose Luis es coautor de la tesis "Reconocimiento y ejecución de laudos anulados en la sede del arbitraje: análisis al amparo de la Convención de Nueva York". Tiene experiencia representando a clientes en arbitrajes de inversión y arbitrajes comerciales. Su experiencia incluye también procedimientos de reconocimiento y ejecución de laudos arbitrales extranjeros bajo la Convención de Nueva York. Correo electrónico: jrepetto@mafirma.com.pe 


\section{Aplicación de la Convención de Nueva York por las cortes Lationamericanas Application of New York Convention by Latin American courts}

approved in New York on June 10, 1958, through the review of the most relevant case-law of the main jurisdictions in arbitration in Latin America. The following article provides a review of the different ground for refusal of recognition that a party can use to oppose the recognition of an award, revealing the criteria used by the courts to enforce or deny recognition of a foreign award.

Keywords: Arbitration - Recognition of Awards - Exequatur Case-Law - Latin America - New York Convention

Sumario: 1. Introducción_2. Premisas generales para la aplicación de las causales de denegación de reconocimiento_3. Jurisprudencia_ 4. Comentarios finales_5. Referencias bibliográficas.

\section{Introducción}

Una de las principales ventajas del arbitraje frente al Poder Judicial es la mayor circulación que tienen los laudos frente a las decisiones judiciales ${ }^{(1)}$. Las decisiones arbitrales son reconocidas con mayor facilidad en comparación que las decisiones judiciales.
En efecto, los tratados que regulan el reconocimiento de sentencias judiciales generalmente son muy limitados, están plagados de formalismos o simplemente tienen deficiencias en cuanto a su aplicación. Pero, además, estas circunstancias muchas veces obligan a que se tengan que aplicar las normas de derecho internacional privado de cada país, las mismas que muchas veces son aún más ineficientes ${ }^{(2)}$.

En cambio, reconocer un laudo arbitral en un territorio distinto del cual se emitió dicho laudo es más sencillo. Ello se debe en gran medida a la Convención sobre el Reconocimiento y la Ejecución de Sentencias Arbitrales Extranjeras, aprobada en Nueva York el 10 de junio de 1958 o también conocida como la Convención de Nueva York. Este tratado tiene 156 Estados parte y es considerada por Born como una suerte de constitución del arbitraje comercial internacional ${ }^{(3)}$. Para la Corte Superior de Justicia de Lima, la Convención de

(1) Gary Born, por ejemplo, destaca lo siguiente: "Like agreements to arbitrate, international arbitral awards enjoy the protection of the New York Convention, as well as favorable arbitration legislation in many countries. (...) these instruments provide a "pro-enforcement" regime, with expedited recognition procedures and only limited grounds for denying recognition to an arbitral award. Particularly in developed trading states, there is substantial, successful experience with the enforcement of international arbitral awards. In contrast, there are only a few regional arrangements for the enforcement of foreign judgments (in particular, Council Regulation 44/2001 in Europe), and there is no global counterpart to the New York Convention for foreign judgments. Some major trading states, including the United States, are party to no bilateral or multilateral agreement on the enforceability of foreign judgments. In the absence of international treaties, the recognition of foreign judgments in many nations is subject to local law, which often makes it difficult or impossible to obtain effective enforcement. As a consequence, there is generally a significantly greater likelihood that an international arbitral award will be enforced abroad, and actually put the parties' dispute to rest, than will a national court judgment. Together with the comparatively greater enforceability of arbitration agreements, the more reliable enforceability of arbitral awards is another one of the basic objectives, and attractions, of international arbitration." Véase Gary Born, International Commercial Arbitration, 2ª ed. (Kluwer Law International, 2014), 79-80.

(2) Véase Fernando Cantuarias Salaverry, Arbitraje Comercial y de las Inversiones (Lima: Fondo Editorial de la UPC, 2007), 32 y siguientes.

(3) "Generally referred to as the "New York Convention," the treaty is by far the most significant contemporary legislative instrument relating to international commercial arbitration. It provides what amounts to a universal constitutional charter for the international arbitral process, whose sweeping terms have enabled both national courts and arbitral tribunals to develop durable, effective means for enforcing international arbitration agreements and arbitral awards. The Convention also provided the basis for most contemporary national legislation governing the international arbitral process, and in particular the UNCITRAL Model Law, which has implemented and elaborated upon the Convention's basic principles and legal framework". Véase Gary Born, International Commercial Arbitration, $2^{a}$ ed. (Kluwer Law International, 2014), 99. 


\section{Fernando Cantuarias Salaverry y Jose Luis Repetto Deville}

Nueva York "constituye la piedra angular del arbitraje comercial internacional" (CSJL 2011).

La región latinoamericana no se ha caracterizado por su amabilidad hacia el arbitraje. Aunque el Perú y un importante grupo de Estados latinoamericanos son parte de la Convención de Nueva York ${ }^{(4)}$, durante décadas la hostilidad fue la regla ${ }^{(5)}$. Sin embargo, esta tendencia parece estar siendo superada por ciertos países latinoamericanos cuyas legislaciones arbitrales siguen los postulados de la Ley Modelo UNCITRAL ${ }^{(6)}$. Ello, refleja el incremento significativo de arbitrajes localizados en ciudades de América Latina y con partes latinoamericanas ${ }^{(7)}$.

La situación antes descrita planteará el problema que, si una parte latinoamericana pierde un arbitraje, el laudo deberá ser reconocido y ejecutado en el país donde la parte latinoamericana tiene sus activos. Por ello, cobra importancia el exequátur del laudo y la Convención de Nueva York.

En este artículo, nos proponemos comentar la aplicación de la Convención de Nueva York por las cortes latinoamericanas a través de la revisión de la jurisprudencia, con especial énfasis en la jurisprudencia peruana.
En primer lugar, se desarrollarán algunas premisas generales respecto a la aplicación de las causales de denegación de reconocimiento. Acto seguido, se describirán los principales pronunciamientos de las cortes peruanas y latinoamericanas que se han emitido sobre este particular. Para ello, hemos compilado los pronunciamientos en razón a la causal que es aplicable.

\section{Premisas generales para la aplicación de las causales de denegación de reconocimiento}

Las causales para denegar un laudo extranjero en un país seguidor de la Ley Modelo UNCITRAL que es parte a su vez de la Convención de Nueva York (e inclusive de la Convención de Panamá), son las previstas en la Convención de Nueva York, que han sido reproducidas en la Convención de Panamá y a la vez recogidas en la Ley Modelo UNCITRAL.

(4) El Perú lo es desde el año 1988. Este país no ha formulado ninguna de las dos reservas permitidas al momento que se adhirió a dicho tratado. La Convención de Nueva York permite formular dos tipos de reservas, la reserva de reciprocidad y la reserva comercial. Si un Estado ha formulado la reserva de reciprocidad al momento de adherirse a la Convención de Nueva York se reconocerán en un Estado parte de la Convención de Nueva York laudos provenientes de un Estado parte de la Convención de Nueva York. Al respecto, el Artículo I(3) de la Convención de Nueva York dispone lo siguiente: "En el momento de firmar o de ratificar la presente Convención, de adherirse a ella o de hacer la notificación de su extensión prevista en el artículo X, todo Estado podrá, a base de reciprocidad, declarar que aplicará la presente Convención al reconocimiento y a la ejecución de las sentencias arbitrales dictadas en el territorio de otro Estado Contratante únicamente.". La otra reserva posible es la denominada reserva comercial, en virtud de la cual los Estados se reservan el derecho de reconocer solo laudos arbitrales comerciales, según lo previsto en su legislación doméstica. Sobre el particular el artículo I(3) de la Convención de Nueva York establece que: "Podrá también declarar que sólo aplicará la Convención a los litigios surgidos de relaciones jurídicas, sean o no contractuales, consideradas comerciales por su derecho interno."

(5) Véase Horacio A. Grigera Naón, "Arbitration and Latin America: Progress and Setbacks", en Arbitration Insights: Twenty Years of the Annual Lecture of the School of International Arbitration, Loukas A. Mistelis and Julian D. M. Lew eds., vol. 16, International Arbitration Law Library (Kluwer Law International, 2007), 393-454.

(6) Perú, Decreto Legislativo 1071, publicado el 28 de junio de 2008; Panamá, Ley 131 del 31 de diciembre de 2013, publicada el 8 de enero de 2014; Chile, Ley 19971, publicada el 29 de setiembre de 2004; México, Decreto del 22 de julio de 1993; Colombia, Ley 1563 de 2012, publicada el 12 de julio de 2012; República Dominicana, Ley 489-08, publicada el 30 de diciembre de 2008; y Costa Rica, Ley 8937, publicada el 25 de mayo de 2011.

(7) Albanesi comentando las estadísticas de la ICC revela que el porcentaje de partes lationamericanas involucradas en arbitrajes ICC se incrementó de $10.5 \%$ en 2008 a $16.9 \%$ en 2014. Asimismo, los arbitrajes localizados en América Latina registraron un incremento del 74\%. En 2009, existieron 27 arbitrajes ICC y en 2014 el número se incrementó a 47. Christian Albanesi, "Advances in International Commercial Arbitration in Latin America during John's Presidency of the ICC Court", en International Arbitration Under Review: Essays in Honour of John Beechey, Andrea Carlevaris, Laurent Lévy, Alexis Mourre, Eric A. Schwartz eds. (ICC, 2015), 13-15. 


\section{Aplicación de la Convención de Nueva York por las cortes Lationamericanas Application of New York Convention by Latin American courts}

Es decir, existe uniformidad en las razones en las que se pueden basar las cortes para denegar el reconocimiento de un laudo extranjero.
En el siguiente cuadro se aprecian las razones y su respectiva redacción, bajo las cuales se puede denegar el reconocimiento de un laudo extranjero:

\begin{tabular}{|c|c|c|c|}
\hline Causal & Ley Modelo UNCITRAL & Convención de Nueva York & Convención de Panamá \\
\hline $\begin{array}{l}\text { Capacidad } \\
\text { y validez del } \\
\text { convenio } \\
\text { arbitral }\end{array}$ & $\begin{array}{l}\text { 36(1)(a)(i) Que una de las partes en el } \\
\text { acuerdo de arbitraje a que se refiere el } \\
\text { artículo } 7 \text { estaba afectada por alguna inca- } \\
\text { pacidad, o que dicho acuerdo no es válido } \\
\text { en virtud de la ley a que las partes lo han } \\
\text { sometido, o si nada se hubiera indicado a } \\
\text { este respecto, en virtud de la ley del país } \\
\text { en que se haya dictado el laudo. }\end{array}$ & $\begin{array}{l}\text { V(1)(a) Que las partes en el acuerdo a que se } \\
\text { refiere el artículo II estaban sujetas a alguna } \\
\text { incapacidad en virtud de la ley que es aplica- } \\
\text { ble o que dicho acuerdo no es válido en virtud } \\
\text { de la ley a que las partes lo han sometido, o } \\
\text { si nada se hubiera indicado a este respecto, } \\
\text { en virtud de la ley del país en que se haya } \\
\text { dictado la sentencia. }\end{array}$ & $\begin{array}{l}\text { 5(1)(a) Que las partes en el acuerdo } \\
\text { estaban sujetas a alguna incapacidad en } \\
\text { virtud de la ley que les es aplicable o que } \\
\text { dicho acuerdo no es válido en virtud de la } \\
\text { ley a que las partes lo han sometido, o si } \\
\text { nada se hubiere indicado a este respecto, } \\
\text { en virtud de la ley del Estado en que se } \\
\text { haya dictado la sentencia; o }\end{array}$ \\
\hline $\begin{array}{l}\text { Violación de } \\
\text { medios de } \\
\text { defensa }\end{array}$ & $\begin{array}{l}\text { 36(1)(a)(ii) Que la parte contra la cual se } \\
\text { invoca el laudo no ha sido debidamente } \\
\text { notificada de la designación de un árbitro } \\
\text { o de las actuaciones arbitrales o no ha } \\
\text { podido, por cualquier otra razón, hacer } \\
\text { valer sus derechos }\end{array}$ & $\begin{array}{l}\mathrm{V}(1)(\mathrm{b}) \text { Que la parte contra la cual se invoca } \\
\text { la sentencia arbitral no ha sido debidamente } \\
\text { notificada de la designación del árbitro o del } \\
\text { procedimiento de arbitraje o no ha podido, por } \\
\text { cualquier otra razón, hacer valer sus medios } \\
\text { de defensa. }\end{array}$ & $\begin{array}{l}\text { 5(1)(b) Que la parte contra la cual se } \\
\text { invoca la sentencia arbitral no haya sido } \\
\text { debidamente notificada de la designación } \\
\text { del árbitro o del procedimiento de arbitraje } \\
\text { o no haya podido, por cualquier otra razón, } \\
\text { hacer valer sus medios de defensa }\end{array}$ \\
\hline $\begin{array}{l}\text { Exceso de } \\
\text { facultades }\end{array}$ & $\begin{array}{l}\text { 36(1)(a)(iii) Que el laudo se refiere a una } \\
\text { controversia no prevista en el acuerdo de } \\
\text { arbitraje o contiene decisiones que exce- } \\
\text { den los términos del acuerdo de arbitraje; } \\
\text { no obstante, si las disposiciones del laudo } \\
\text { que se refieren a las cuestiones sometidas } \\
\text { al arbitraje pueden separarse de las que } \\
\text { no lo están, se podrá dar reconocimiento y } \\
\text { ejecución a las primeras. }\end{array}$ & $\begin{array}{l}\text { V(1)(c) Que la sentencia se refiere a una } \\
\text { diferencia no prevista en el compromiso o no } \\
\text { comprendida en las disposiciones de la cláu- } \\
\text { sula compromisoria, o contiene decisiones } \\
\text { que exceden de los términos del compromiso } \\
\text { o de la cláusula compromisoria; no obstante, } \\
\text { si las disposiciones de la sentencia que } \\
\text { se refieren a las cuestiones sometidas al } \\
\text { arbitraje pueden separarse de las que no } \\
\text { han sido sometidas al arbitraje, se podrá dar } \\
\text { reconocimiento y ejecución a las primeras. }\end{array}$ & $\begin{array}{l}\text { 5(1)(c) Que la sentencia se refiera a una } \\
\text { diferencia no prevista en el acuerdo de las } \\
\text { partes de sometimiento al procedimiento } \\
\text { arbitral; no obstante, si las disposiciones } \\
\text { de la sentencia que se refieren a las cues- } \\
\text { tiones sometidas al arbitraje pueden sepa- } \\
\text { rarse de las que no hayan sido sometidas } \\
\text { al arbitraje, se podrá dar reconocimiento y } \\
\text { ejecución a las primeras }\end{array}$ \\
\hline \begin{tabular}{|l|} 
Violación del \\
pacto de las \\
partes o de la \\
ley de arbitraje
\end{tabular} & $\begin{array}{l}\text { 36(1)(a)(iv) Que la composición del tribunal } \\
\text { arbitral o el procedimiento arbitral no se } \\
\text { han ajustado al acuerdo celebrado entre } \\
\text { las partes o, en defecto de tal acuerdo, que } \\
\text { no se han ajustado a la ley del país donde } \\
\text { se efectuó el arbitraje. }\end{array}$ & $\begin{array}{l}\text { V(1)(d) Que la constitución del Tribunal Arbi- } \\
\text { tral o el procedimiento arbitral no se han ajus- } \\
\text { tado al acuerdo celebrado entre las partes o, } \\
\text { en defecto de tal acuerdo, que la constitución } \\
\text { del Tribunal Arbitral o el procedimiento arbitral } \\
\text { no se han ajustado a la ley del país donde se } \\
\text { ha efectuado el arbitraje. }\end{array}$ & $\begin{array}{l}5(1)(d) \text { Que la constitución del tribunal } \\
\text { arbitral o el procedimiento arbitral no se } \\
\text { hayan ajustado al acuerdo celebrado entre } \\
\text { las partes o, en defecto de tal acuerdo, } \\
\text { que la constitución del tribunal arbitral } \\
\text { o el procedimiento arbitral no se hayan } \\
\text { ajustado a la ley del Estado donde se haya } \\
\text { efectuado el arbitraje; }\end{array}$ \\
\hline $\begin{array}{l}\text { Laudo aún no } \\
\text { obligatorio, } \\
\text { anulado o } \\
\text { suspendido }\end{array}$ & $\begin{array}{l}\text { 36(1)(a)(v) Que el laudo no es aún obli- } \\
\text { gatorio para las partes o ha sido anulado } \\
\text { o suspendido por un tribunal del país en } \\
\text { que, o conforme a cuyo derecho, ha sido } \\
\text { dictado ese laudo }\end{array}$ & $\begin{array}{l}\text { V(1)(e) Que la sentencia no es aún obligatoria } \\
\text { para las partes o ha sido anulada o suspendi- } \\
\text { da por una autoridad competente del país en } \\
\text { que, o conforme a cuya ley, ha sido dictada } \\
\text { esa sentencia. }\end{array}$ & $\begin{array}{l}\text { 5(1)(e) Que la sentencia no sea aún } \\
\text { obligatoria para las partes o haya sido } \\
\text { anulada o suspendida por una autoridad } \\
\text { competente del Estado en que, o conforme } \\
\text { a cuya ley, haya sido dictada esa sentencia }\end{array}$ \\
\hline $\begin{array}{l}\text { Materia no } \\
\text { arbitrable }\end{array}$ & $\begin{array}{l}\text { 36(1)(b)(i) Que, según la ley de este } \\
\text { Estado, el objeto de la controversia no es } \\
\text { susceptible de arbitraje. }\end{array}$ & $\begin{array}{l}\text { V(2)(a) Que, según la ley de ese país, el } \\
\text { objeto de la diferencia no es susceptible de } \\
\text { solución por vía de arbitraje. }\end{array}$ & $\begin{array}{l}\text { 5(2)(a) Que, según la ley de este Estado, } \\
\text { el objeto de la diferencia no es susceptible } \\
\text { de solución por vía de arbitraje }\end{array}$ \\
\hline $\begin{array}{l}\text { Violación del } \\
\text { orden público }\end{array}$ & $\begin{array}{l}\text { 36(1)(b)(ii) Que el reconocimiento o la } \\
\text { ejecución del laudo serían contrarios al } \\
\text { orden público de este Estado. }\end{array}$ & $\begin{array}{l}\text { V(1)(b) Que el reconocimiento o la ejecución } \\
\text { de la sentencia serían contrarios al orden } \\
\text { público de ese país. }\end{array}$ & $\begin{array}{l}\text { 5(2)(b) Que el reconocimiento o la eje- } \\
\text { cución de la sentencia sean contrarios al } \\
\text { orden público del mismo Estado. }\end{array}$ \\
\hline
\end{tabular}




\section{Fernando Cantuarias Salaverry y Jose Luis Repetto Deville}

Como se puede apreciar, existe una marcada similitud en la redacción de las causales de denegación de reconocimiento previstas en todos los dispositivos normativos.

Ahora bien, conviene mencionar algunas premisas generales o comunes con respecto a la aplicación de las causales para denegar el reconocimiento.

\subsection{Las causales son taxativas y no pueden ser ampliadas vía interpretación}

En primer lugar, las causales para denegar el reconocimiento de un laudo extranjero solo son aquellas que se encuentran previstas en la Convención de Nueva York. Es decir, no pueden existir más causales que las dispuestas en dicho tratado. Las razones son exhaustivas y los Estados no pueden establecer razones adicionales para denegar el reconocimiento de un laudo.

El texto de la Convención de Nueva York establece que "sólo se podrá denegar el reconocimiento y la ejecución de la sentencia, a instancia de la parte contra la cual es invocada, si esta parte prueba ante la autoridad competente del país en que se pide el reconocimiento y la ejecución" (Convención de Nueva York, artículo V[1]) (la cursiva es del autor). La literalidad del tratado revela que las razones son exhaustivas.

Respecto a ello, la Corte Suprema de Colombia, en el caso Drummond Ltd. vs. Instituto Nacional de Concesiones, ha establecido que:

"Preliminarmente debe destacarse que la Convención de Nueva York de 1958 incorporó un catálogo integral de los motivos que conducen a la denegación de la homologación de un laudo arbitral extranjero (...) lo dicho conlleva la imposibilidad de invocar, y menos acoger causas distintas a las allí previstas" (SCJ of Colombia 2012)(8).
En el mismo sentido, la Corte Superior de Justicia de Lima, acertadamente ha dispuesto que:

"hay que destacar que la Convención de Nueva York prevé su artículo $\mathrm{V}$ siete causales taxativas por las que se puede denegar el reconocimiento y ejecución de un laudo extranjero" (CSJL 2011).

\subsection{Las causales deben ser interpretadas restrictivamente}

En la misma línea que lo expuesto en el acápite anterior, las causales de denegación de reconocimiento de un laudo extranjero deben ser interpretadas restrictivamente. Es una obviedad que lo taxativo se interpreta de modo restrictivo ya que, de lo contrario, las causales no serían taxativas sino un número abierto.

La jurisprudencia colombiana, específicamente la Corte Suprema de Colombia ha determinado que las causales de denegación de reconocimiento son excepcionales. En efecto, al decidir el caso Empresa de Generación Eléctrica del Sur vs. Consorcio Pisco, se indicó que:

"las causales exhaustivas [de la Convención] que son excepcionales y calificadas en su naturaleza (...) que deben ser invocadas por el demandado o excepcionalmente apreciadas de oficio, son compatibles con el artículo 36 [de la Ley Modelo UNCITRAL] en concordancia con el artículo 34 de dicha Ley" (SCJ of Colombia 2016) ${ }^{(9)}$.

(8) Traducción libre de: "Preliminarily, we must stress that the 1958 New York Convention contains an exhaustive list of the grounds which lead to refusing the homologation of a foreign arbitral award (...) Thus it is impossible to invoke and even less grant other grounds than those therein provided".

(9) Traducción libre de: "The exhaustive grounds [in the Convention], which are of an exceptional and qualified nature and can by themselves weaken a non-domestic award and be raised in principle by the defendant or be exceptionally declared ex officio, are compatible with Art. 36 of [the UNCITRAL Model Law], (5) in accordance with Art. 34 of that Law." 


\section{Aplicación de la Convención de Nueva York por las cortes Lationamericanas Application of New York Convention by Latin American courts}

La Primera Sala Comercial de la Corte Superior de Justicia de Lima en un caso de anulación de un laudo dictado en el Perú, pero igualmente aplicable al reconocimiento de laudos por la similitud del lenguaje utilizado en la regulación de las causales de anulación, ha señalado correctamente que:

“(...) las causales por las que puede ser anulado un laudo arbitral, las que deben ser interpretadas de manera restrictiva" (CSJL 2013b).

\subsection{Existen causales a petición de parte y causales que pueden ser apreciadas de oficio por el Poder Judicial \\ Relacionado con lo anterior, se debe precisar que las causales de denegación del reconocimiento deben, en principio, ser alegadas y probadas por la parte que se opone al reconocimiento del laudo extranjero. Es decir, la carga de la prueba de que el laudo no se reconozca recae en la parte que se opone a su reconocimiento. Es esta quien debe probar alguna de las causales taxativamente enumeradas para que se deniegue el reconocimiento del laudo. Por consiguiente, existe una presunción de validez del laudo bajo la Convención de Nueva York.}

Sin perjuicio de lo anterior, dos causales pueden ser apreciadas de oficio por las Cortes que se enfrentan al pedido de reconocimiento de un laudo extranjero. La primera causal, es que el objeto de la controversia no sea manifiestamente susceptible de ser sometido a arbitraje en la sede y, la segunda, es que el laudo sea contrario al orden público internacional de la sede.

En esas circunstancias, no es necesario invocar la causal por la parte que se opone al reconocimiento del laudo. Los jueces son quienes pueden apreciar si corresponde invocar la causal.

Sobre este tema, la Corte Suprema de Chile, al decidir el caso Comverse Inc. vs. American Telecommunication Inc., sostuvo que:
"El artículo 36 que reproduce el artículo $\checkmark$ de la Convención de Nueva York, enumera las razones por las cuales el reconocimiento y ejecución puede ser denegado, independientemente del lugar donde se emitió el laudo. Ambas disposiciones establecen que el reconocimiento de un laudo puede ser denegado, a pedido de la parte contra la cual es invocada, solo si esa parte prueba ante la autoridad competente donde se solicita el reconocimiento y ejecución una de las causales referidas más adelantes en dicho artículo" (SCJ of Chile 2009a) ${ }^{(10)}$.

Adicionalmente, la Corte Suprema de Justicia de Colombia ha indicado que:

"Respecto a las causales del artículo $V$ que permite a la corte ha denegar el reconocimiento, debemos especificar que existen aquellas (1) que deben ser probadas por el demandado de (2) aquellas que puede ser evaluadas de oficio" (SCJ of Colombia 2011) $)^{(11) .}$

Sobre este tema, la Corte Superior de Justicia de Lima considera que:

“(...) de las referidas siete causales [para denegar el reconocimiento], cinco pueden ser invocadas por la parte contra la cual se pretende ejecutar el laudo cuyo reconocimiento y ejecución se solicita (causales alegables exclusivamente a instancia de parte), y dos de están referidas a la inarbitrabilidad de la disputa y al orden público del lugar donde se

(10) Traducción libre de: "Art. 36, which reproduces Art. V of the New York Convention, lists the grounds on which recognition and enforcement of an arbitral award may be denied, independent of the country where the award was rendered. Both provisions state that recognition and enforcement of the award may be denied, at the request of the party against whom it is invoked, only if that party proves to the competent court of the country where recognition and enforcement is sought one of the grounds referred to later in the provision (...)".

(11) Traducción libre de: "“In respect of the grounds on which [Art. V] allows [the court] to refuse homologation, we specify that those under (1) must be proved by the defendant, while those under (2) may be found ex officio, when proven". 


\section{Fernando Cantuarias Salaverry y Jose Luis Repetto Deville}

tramita el reconocimiento y ejecución, y a diferencia de las cinco primeras, estas últimas si pueden ser invocadas de oficio por la autoridad competente del país en que se solicita el reconocimiento y ejecución del laudo extranjero (estimables de oficio)" (CSJL 2011).

En consecuencia, es claro que la carga de acreditar las cinco primeras causales para denegar el reconocimiento recae en la parte que se opone al reconocimiento y las últimas dos competen a la propia Corte ante la cual se tramita el reconocimiento.

\subsection{No cabe revisar el fondo de la controversia}

Otro punto importante que involucra la aplicación de las causales para denegar el reconocimiento de un laudo extranjero, es que los jueces al decidir el exequátur tienen prohibido, bajo responsabilidad, revisar el fondo de la controversia. Es decir, los jueces no pueden evaluar los criterios que se encuentran contenidos en el laudo.

En relación a esto, la Corte Suprema de Justicia de Colombia, en el caso Empresa de Generación Eléctrica del Sur - Egesur S.A. vs. Consorcio Pisco, estableció que:

"el reconocimiento no es una evaluación de lo correcto de una decisión arbitral o de las premisas de hecho o de derecho, o de las conclusiones fácticas de una corte extranjera o del árbitro conforme a su derecho nacional en relación con la fuerza o los méritos. Por el contrario, el reconocimiento es un proceso de confirmar si un laudo tiene efectos o será ejecutado en Colombia. No es un análisis del sustento del caso; de lo contrario, la construcción de la comunidad internacional del mundo globalizado se vería disminuida. La Corte no puede revisar las normas sustantivas para decidir el reconocimiento y si estas coinciden exactamente con las normas colombianas" (SCJ of Colombia 2016)(12).
La Corte Suprema de Chile, al decidir el caso Qisheng Resources Limited vs. Minera Santa $\mathrm{Fe}$, indicó que:

"este procedimiento [reconocimiento] no es un procedimiento en los méritos, por lo tanto, los puntos jurídicos o de hecho discutidos en el arbitraje bajo el se emitió el laudo no pueden ser invocados o decididos [en el proceso de reconocimiento]. NI los argumentos discutidos en el arbitraje pueden constituir una defensa o una objeción para el reconocimiento" (SCJ of Chile 2016) $)^{(13)}$.

En el mismo sentido, la Corte Superior de Justicia de Lima ha establecido que:

"Tanto el reconocimiento de una sentencia como el laudo dictado por un Tribunal extranjero, requieren para su eficacia en el país, de un procedimiento especial, denominado exequátur, en mérito del cual las sentencias o laudos firmes dictados en el exterior, pueden producir el efecto de cosa juzgada o ser ejecutadas en otro Estado, siempre y cuando reúnan los requisitos que permitan su homologación. De ahí que, el citado procedimiento presenta una naturaleza 'homologadora' en donde el órgano jurisdiccional encargado del mismo no puede entrar a conocer del fondo del asunto, limitándose (con excepción de la posible contrariedad con el orden público) a verificar determinados aspectos formales, conforme lo determina el Código Procesal Civil en sus artículos 837 y siguientes, como

(12) Traducción libre de: "recognition is not an examination to correct the arbitral decision as to its premises of fact or law, or the factual conclusions of the foreign court or arbitrator in accordance with the national law, in respect of their strength and merits. On the contrary, recognition is a procedure for confirming an award so that it can have its effects or be enforced in Colombia. It is not an analysis of the 'sustratum' of the case; otherwise, the building of the international community of the globalized world would be undermined. The Court may not review the substantive norms underlying the decision so that they exactly coincide with the Colombian norms".

(13) Traducción libre de: "this proceeding [recognition] is not a proceeding on the merits [instancia], so that factual and legal issues discussed in the action in which the foreign arbitral award was rendered cannot be raised or decided [here]." 


\section{Aplicación de la Convención de Nueva York por las cortes Lationamericanas Application of New York Convention by Latin American courts}

también los requisitos establecidos por el artículo 2104 y demás pertinentes del Código Civil" (CSJL 2016a).

En el mismo sentido, se han pronunciado la Corte Suprema de Argentina ${ }^{(14)}$ y la Corte Superior de Justicia de Brasil(15).

Por lo tanto, como correctamente han dictaminado las cortes latinoamericanas, en vía de exequátur no cabe revisar el fondo de la controversia.

\section{Jurisprudencia}

Luego de haber explicado las premisas generales respecto a cómo se aplican las causales para denegar el reconocimiento de un laudo extranjero, corresponde realizar un breve análisis de la jurisprudencia de las cortes latinoamericanas, causal por causal, para conocer cómo se ha pronunciado frente a los pedidos de reconocimiento de laudos extranjeros.

\subsection{Causal V(1)(A): Capacidad y validez del convenio arbitral \\ De acuerdo con el artículo $\mathrm{V}(1)(\mathrm{A})$ de la Convención de} Nueva York, el laudo podrá ser anulado si "las partes en el acuerdo a que se refiere el artículo II estaban sujetas a alguna incapacidad en virtud de la ley que es aplicable o que dicho acuerdo no es válido en virtud de la ley a que las partes lo han sometido, o si nada se hubiera indicado a este respecto, en virtud de la ley del país en que se haya dictado la sentencia." Esta causal está relacionada, pues, con la validez y eficacia del convenio arbitral, así como la capacidad de quien consiente el arbitraje.

En al menos tres oportunidades, las cortes latinoamericanas se han pronunciado con respecto a esta causal: (i) Mandate
Holdings LLC vs. Consorcio Europa; (ii) Huawei do Brasil Telecouminicacoes Ltda. vs. Zune Consultoria de Telecomunicaoes Ltda.; y, (iii) Thyssenkrupp Steel Europe AG vs. Companhia Siderurgica Nacional CSN. A continuación, abordaremos cada uno de ellos.

3.1.1 Mandate Holdings LLC vs. Consorcio Europa (Brazil)

En este caso, la controversia se remonta a un acuerdo de licencia para la distribución de la película El Grito suscrita por Mandate Holdings LLC (En adelante, "Mandate") and Consorcio Europa en el 2013. Dicho contrato remitía a arbitraje las futuras controversias que se deriven del mismo bajo la administración de la Independent Film \& Television Alliance.

Surgida una disputa, Mandate presentó una solicitud de arbitraje contra Consorcio Europa. Según los registros, el demandado no participó en el arbitraje a pesar de ser debidamente notificado. El tribunal arbitral laudó a favor de Mandate.

Emitido el laudo arbitral, Mandate solicitó el reconocimiento ante las cortes brasileñas. Entre otras defensas que fueron objeto de debate en el proceso de reconocimiento y que serán comentadas en otros extremos de este artículo, Consorcio Europa se opuso al reconocimiento porque el contrato, al ser uno de adhesión, establecía formalidades adicionales que no habían sido observadas.

(14) Véase Armada Holland BV vs. Inter Fruit S.A., Supreme Court of Justice of Argentina, May 24, 2011. En Yearbook Commercial Arbitration 2014, Albert Jan van den Berg ed., vol. XXXIX, (Kluwer Law International, 2014), 6: "“The verification of compliance with the conditions provided for in Act no. 23.619 regarding enforcement of an arbitral award does not warrant any revision or modification of the decision on the merits made by the arbitrator, the court being competent only to verify the fulfillment the above-mentioned conditions."

(15) Véase CIMC Raffles Offshore Limited y otros vs. Schahin Holding SA y otros, Superior Tribunal de Justiça of Brazil, SEC No. 9880 - EX (2013/0296479-3), May, 21 2014. En Yearbook Commercial Arbitration 2015, Albert Jan van den Berg ed., vol. XL, (Kluwer Law International, 2015), 11: "In this context, this Superior Court of Justice cannot, in the homologation proceeding, find that the arbitral award is null and void without interfering with the jurisdiction of the arbitral tribunal. Further, a review of this argument requires a foray into the merits of the contractual provisions established by the parties, which is not allowed in homologation proceedings". 


\section{Fernando Cantuarias Salaverry y Jose Luis Repetto Deville}

La Corte Superior de Justicia de Brazil no amparó dicha razón, porque consideró que el reconocimiento de un laudo "se encuentra limitado a un análisis de requisitos formales, la revisión de los méritos de una decisión extranjera cuya ejecución se solicita en Brasil es inaceptable" (SCJB 2013)(16).

A pesar de que la corte bien pudo explayarse en cuanto a las razones, lo cierto es que el resultado fue correcto. La parte demandada buscaba que se deniegue el reconocimiento del laudo porque el contrato, y no el convenio arbitral, no había presuntamente respetado las formalidades correspondientes. Es decir, el cuestionamiento estaba referido a una cuestión sustantiva (validez del contrato) y no a la validez misma del convenio arbitral. Por ello, es correcto que la corte haya indicado que el cuestionamiento no se encontraba comprendido en la causal.

3.1.2. Huawei do Brasil Telecouminicacoes Ltda. vs. Zune Consultoria de Telecomunicaoes Ltda. (Brazil)

En este caso, Huawei do Brasil Telecouminicacoes Ltda. (En adelante, "Huawei") y Zune Consultoria de Telecomunicaoes Ltda. (En adelante, "Zune") celebraron un contrato, el cual establecía que las disputas podían ser referidas a un arbitraje administrado por la Hong Kong International Arbitration Center (En adelante, "HKIAC").

Resulta que se generó una controversia entre las partes antes referidas que desencadenó en un arbitraje administrado por la HKIAC. Los árbitros emitieron un laudo favorable a Huawei.

Huawei solicitó el reconocimiento del laudo ante las cortes brasileñas. Zune se opuso al reconocimiento sobre la base que no existía un convenio arbitral vinculante. En específico, Zune argumentó que la redacción utilizada en el convenio arbitral denotaba un lenguaje opcional y no obligatorio.

La Corte Superior de Justicia de Brasil rechazó el argumento de Zune y procedió a reconocer el laudo. En concreto, sostuvo que las partes al incluir el convenio arbitral obviamente querían convenir el arbitraje, porque de lo contrario no hubiesen introducido una cláusula arbitral. En palabras de la Corte Superior de Justicia de Brasil:

"Cuando las partes aceptaron el convenio arbitral resulta obvio que convinieron que las controversias se resuelvan ante un tribunal arbitral, de lo contrario no existiría razón para convenir una cláusula arbitral con ese objetivo. Por consiguiente, habiendo las partes elegido el foro arbitral a través de una cláusula arbitral, las partes están obligadas a someterse con relación a cualquier posible disputa en su contrato" $\left(\right.$ STJB 2015a) ${ }^{(17)}$.

Creemos que la decisión de la Corte Superior de Justicia de Brasil es correcta. La discusión era si las partes habían consentido el arbitraje. Es obvio que el hecho que las partes hayan incluido una cláusula arbitral debe tener efecto legal, a pesar del lenguaje poco feliz de la cláusula.

3.1.3. Thyssenkrupp Steel Europe AG vs. Companhia Siderurgica Nacional CSN

En este caso, Thyssenkrupp Steel Europe AG (En adelante, "Thyssen") y Companhia Siderurgica Nacional (En adelante, "CSN") establecieron un joint-venture para crear una empresa brasileña denominada Galvasalud. En agosto de 1999, Thyssen y Galvasalud celebraron un Offtake Agreement para el suministro de materiales. Este acuerdo refería las futuras disputas a arbitraje a ser resuelto por un árbitro y administrado por la Cámara de Comercio Internacional ("ICC", por sus siglas en inglés) con sede en Dusseldorf.

(16) Traducción libre de: “"is limited to an analysis of formal requirements, the review of the merits of the foreign decision whose effectiveness in [Brazil] is sought being unacceptable".

(17) Traducción libre de: "when the parties accepted the arbitration agreement, it seems obvious that they agreed on the validity of the settlement of possible disputes before the arbitral tribunal, otherwise there would be no reason to conclude a clause to this purpose. Hence, having chosen an arbitral forum through an arbitration clause, the parties are subject thereto in respect of a possible dispute as to their contract". 


\section{Aplicación de la Convención de Nueva York por las cortes Lationamericanas Application of New York Convention by Latin American courts}

Posteriormente, en junio de 2004, Thyssen y Galvasalud terminaron el joint-venture y CSN adquirió todas las acciones de Galvasalud, integrándose a esta.

En ese contexto, Thyssen y CSN celebraron un contrato para la terminación de determinados contratos. Este acuerdo mencionaba al Offtake Agreement y refería las futuras controversias a un arbitraje administrado por la ICC, ante tres árbitros y con sede en Río de Janeiro.

Resulta que se originó una controversia relacionada con el Offtake Agreement y Thyssen inició un arbitraje en Dusseldorf, al amparo de la cláusula arbitral prevista en el Offtake Agreement. Luego del desarrollo del arbitraje, se emitió un laudo favorable a Thyssen.

Thyssen solicitó el reconocimiento del laudo en Brasil. Sin embargo, la Corte Superior de Justicia de Brasil denegó el reconocimiento, porque el laudo había sido emitido por una autoridad no competente.

En efecto, luego de analizar los contratos celebrados entre las partes, la Corte Superior de Justicia de Brasil determinó que el Termination Agreement, el cual tenía su propio convenio arbitral, había dejado sin efecto al Offtake Agreement. Por consiguiente, el laudo había sido emitido por una autoridad no competente.

Con respecto a este caso, se debe tener en cuenta que la modificación de un convenio arbitral que extingue el primer convenio arbitral es, en efecto, una razón para denegar el reconocimiento de un laudo, porque (a) el primer convenio arbitral no es válido (al haber sido dejado sin efecto por consentimiento de las partes) o, (b) el segundo convenio arbitral no fue respetado al amparo de la causal V(1)(D). En consecuencia, la decisión de la corte aparece como correcta.

\subsection{Causal V(1)(B): Violación de medios de defensa}

De acuerdo con el artículo V(1)(B) de la Convención de Nueva York, el laudo podrá ser anulado si "la parte contra la cual se invoca la sentencia arbitral no ha sido debidamente notificada de la designación del árbitro o del procedimiento de arbitraje o no ha podido, por cualquier otra razón, hacer valer sus medios de defensa." En al menos dos oportunidades, las cortes latinoamericanas se han pronunciado con respecto a esta causal: (i) Mandate Holdings LLC vs. Consorcio Europa; y, (ii) Qisheng Resources Limited vs. Minera Santa Fe.

\subsubsection{Mandate Holdings LLC vs. Consorcio Europa}

En este caso descrito anteriormente, otra de las razones argumentadas por Consorcio Europa fue que no había sido notificado propiamente de las actuaciones arbitrales a través de carta rogatoria.

La Corte Superior de Justicia de Brasil también rechazó este argumento. En específico, se resolvió que el requisito de ser notificado por carta rogatoria no tiene asidero en el caso de arbitrajes. Como bien puntualizó la corte: "no es necesario las notificaciones por carta rogatoria en el contexto de procedimientos arbitrales" (SCJB 2013). Consideramos que la decisión de la corte es correcta.

3.2.2. Qisheng Resources Limited vs. Minera Santa Fe

En este caso, Qisheng Resources Limited (En adelante, "Qisheng") celebró un contrato con Minera Santa Fe, en virtud del cual Qisheng se obligó a comprar hierro. La cláusula de resolución de disputas remitía las controversias a un arbitraje administrado por la ICC, con sede en París.

Surgida una controversia entre las partes, Qisheng inició un arbitraje contra Minera Santa $\mathrm{Fe}$, que resultó en un laudo favorable para Qisheng.

Qisheng solicitó el reconocimiento del laudo ante el Poder Judicial chileno. Minera Santa $\mathrm{Fe}$ alegó diversas causales para que no se reconozca el laudo en territorio chileno. Entre otras razones, Minera Santa Fe sostuvo que no se había respetado el debido proceso, porque los árbitros permitieron a Qisheng presentar evidencia fuera de la etapa probatoria.

La Corte Suprema de Chile rechazó el planteamiento de Minera Santa Fe. En 


\section{Fernando Cantuarias Salaverry y Jose Luis Repetto Deville}

concreto, la corte expresó que Minera Santa Fe tuvo oportunidad para responder a la evidencia presentada de manera extemporánea por Qisheng. Al respecto, la Corte Suprema de Chile determinó que:

"Debemos notar que aparece claramente de los propios argumentos de la demandada que la demandada no solo se le permitió ejercer su derecho de defensa, sino que también participó en el arbitraje, presentando argumentos y pudo defenderse conforme consta del expediente. Por consiguiente, la demandada no fue privada de su derecho garantizado constitucionalmente a la defensa" (SCJ de Chile 2016) $)^{(18)}$.

Creemos que el razonamiento y el resultado es correcto. Conforme expresó la corte, la demandada tuvo oportunidad de responder la nueva prueba presentada por la demandante $y$, por ende, no afectó su derecho de defensa.

\subsection{Causal V(1)(C): Exceso de facultades}

Conforme al artículo V(1)(c) de la Convención de Nueva York, el laudo podrá ser anulado si "la sentencia se refiere a una diferencia no prevista en el compromiso o no comprendida en las disposiciones de la cláusula compromisoria, o contiene decisiones que exceden de los términos del compromiso o de la cláusula compromisoria; no obstante, si las disposiciones de la sentencia que se refieren a las cuestiones sometidas al arbitraje pueden separarse de las que no han sido sometidas al arbitraje, se podrá dar reconocimiento y ejecución a las primeras". En al menos una oportunidad reportada, las cortes tuvieron la oportunidad de pronunciarse acerca de esta causal. Esto ocurrió en el caso Ji Ye International Limited vs. Pesquera Natalia S.A.C., resuelto por la Corte Superior de Justicia de Lima.

En este caso, Ji Ye International Limited (En adelante, "Ji Ye") celebró un contrato de compraventa internacional de harina de pescado con Pesquera Natalia S.A.C. (En adelante, "Pesquera Natalia"), en virtud del cual esta última se obligó a vender 2,000 toneladas métricas de harina de pescado, las cuales debían ser entregadas en un plazo no mayor de 4 meses a Ji Ye. A cambio, Ji Ye debía pagar 1,300 dólares por tonelada métrica de harina de pescado a través de una carta de crédito. El contrato establecía que las controversias que se derivaran del mismo debían remitirse a un arbitraje con sede en Londres, administrado por la GAFTA.

El tribunal arbitral emitió un primer laudo en el cual rechazó la demanda interpuesta por Ji Ye. Ante ello, Ji Ye apeló la decisión conforme a las reglas de dicha institución arbitral (que permite recurrir ante una segunda instancia arbitral), siendo resuelta la controversia por otro tribunal arbitral. Este último rindió un laudo a favor de Ji Ye. A través de dicho laudo, los árbitros decidieron que Pesquera Natalia debía pagar a favor de Ji Ye la suma de 860,000 dólares. Además, los árbitros decidieron que si las partes no se ponían de acuerdo en los gastos arbitrales, entonces serían fijados por el Tribunal Arbitral.

Ji Ye solicitó el reconocimiento del laudo en el Perú. Pesquera Natalia se apersonó al procedimiento y solicitó que se anule el laudo alegando la causal prevista en el artículo 75(1) (c) de la Ley de Arbitraje, de idéntica redacción al artículo $\mathrm{V}(1)(\mathrm{C})$ de la Convención de Nueva York, toda vez que a su entender, los gastos arbitrales eran una controversia no prevista en el acuerdo arbitral. Según argumentó Pesquera Natalia, el laudo había dictaminado que esos gastos serían fijados por el tribunal arbitral si las partes no se ponían de acuerdo.

Respecto al pedido de anulación del laudo, la Corte Superior señaló correctamente que en el proceso de reconocimiento no es posible anular

(18) Traducción libre de: "we must note that it appears clearly from Defendant's own statements that Defendant not only was not prevented from exercising its right to defend itself but also that, as it acknowledges, it participated in the arbitration, presenting arguments and means of defense, as it appears from the record. Hence, Defendant was not deprived of the constitutionally guaranteed right to rely on its means of defense". 


\section{Aplicación de la Convención de Nueva York por las cortes Lationamericanas Application of New York Convention by Latin American courts}

un laudo, toda vez que ello debe ser tramitado en vía de acción y de conformidad con la legislación arbitral del lugar del arbitraje:

"para nuestro sistema jurídico nacional, La Ley de Arbitraje, aprobada por Decreto Legislativo $\mathrm{N}^{\circ}$ 1071, ha regulado de manera expresa el recurso de anulación y, con mayor precisión, las causales que podrían dar lugar a que un Laudo arbitral se declare nulo, pero éste, debe ser tramitado en vía de acción, no siendo jurídicamente posible dilucidar las causales de anulación al interior del proceso de reconocimiento; el cual, por su naturaleza tiene particular trámite para la citada incidencia; sin perjuicio de verificar la legislación aplicable al caso en concreto (lugar de emisión del Laudo cuestionado), motivaciones por las que lo procurado en el escrito de contradicción debe denegarse" (CSJL 2013a).

Por otro lado, y contrariamente a lo alegado por Pesquera Natalia, la Corte Superior consideró correctamente que los gastos arbitrales sí se encontraban dentro del alcance del convenio arbitral. En efecto, a pesar de que no se haya incluido la referencia a los costos y costas dentro de la cláusula arbitral, lo cierto es que se originan con ocasión de un arbitraje, por lo que se entienden comprendidos dentro del alcance del convenio arbitral.

\subsection{Causal (V)(1)(D): Violación del pacto de las partes} Conforme al artículo V(1)(D) de la Convención de Nueva York, el laudo podrá ser anulado si "Que la constitución del Tribunal Arbitral o el procedimiento arbitral no se han ajustado al acuerdo celebrado entre las partes o, en defecto de tal acuerdo, que la constitución del Tribunal Arbitral o el procedimiento arbitral no se han ajustado a la ley del país donde se ha efectuado el arbitraje". Al igual que en el caso de la causal anterior, en al menos una oportunidad reportada, las cortes tuvieron la oportunidad de pronunciarse respecto a esta causal. Esto ocurrió en el caso Mercovia S/A vs. Comissao Mista Argentino Brasileira (Brazil).

En este caso, una corte brasileña tuvo que decidir si el hecho de que una de las partes inicie el arbitraje con posterioridad al plazo establecido en el convenio arbitral, constituía una violación del pacto de las partes.
El origen de este caso se remonta a una decisión de los gobiernos de Brasil y Argentina de construir un puente sobre el Río Uruguay. La comisión mixta creada por ambos gobiernos, es decir la Comisión Mixta Argentino Brasileña (En adelante, "COMAB") celebró varios contratos con varias empresas constructoras para desarrollar las obras. Uno de estos contratos fue celebrado con Mercovía.

En dicho contrato, surgió una controversia en relación con los pagos de la liquidación de la obra que habían sido objeto de una transacción. Mercovía obtuvo un laudo favorable y solicitó el reconocimiento del mismo en Brasil.

En el proceso de reconocimiento, COMAB solicitó que se deniegue el reconocimiento, porque el convenio arbitral no había sido respetado en el arbitraje. En específico, COMAB argumentó que el plazo máximo para solicitar el arbitraje previsto en el convenio arbitral no se había respetado.

La Corte Superior de Justicia de Brasil rechazó dicho argumento y procedió a reconocer el laudo. En concreto, la corte indicó que COMAB debió formular su reclamo expreso en el arbitraje y no podía esperar al proceso de reconocimiento para recién plantearlo.

En palabras de la Corte:

"el argumento presentado por el demandante en su oposición - la alegada falta de respeto de tiempo para iniciar el arbitraje - no puede tener éxito porque debió haber sido planteado en el arbitraje y no al momento de responder el reconocimiento del laudo" (STJB 2015b) ${ }^{(19)}$.

(19) Traducción libre de: “(...) the arguments raised by the present Defendant in its statement - the alleged lack of standing of COMAB to be a defendant in the arbitration ... and the time limit for the commencement of the arbitration proceeding - cannot succeed, since they should have been raised in the arbitration and not at the stage of the recognition of the contested award". 


\section{Fernando Cantuarias Salaverry y Jose Luis Repetto Deville}

Estamos de acuerdo con el razonamiento de la Corte Superior de Justicia de Brasil, porque es correcto concluir que si una parte no objeta ante el tribunal arbitral cualquier violación del acuerdo de las partes o de alguna disposición de la ley de arbitraje de la sede, se entiende que dicha parte está consintiendo la violación o renunciando a cualquier reclamo futuro. Lo que se busca evitar son decisiones sorpresivas de supuestos vicios que pudieron ser corregidos por el tribunal arbitral en el mismo arbitraje. Por ello, en el caso de la causal $\mathrm{V}(1)(\mathrm{D})$ se debe prestar especial atención a que el reclamo haya sido formulado de modo expreso ante el propio tribunal arbitral.

\subsection{Causal V(1)(E): Laudo no obligatorio, anulado o suspendido}

De acuerdo con el artículo $\mathrm{V}(1)(\mathrm{E})$ de la Convención de Nueva York, se podrá denegar el reconocimiento de un laudo extranjero si el laudo "no es aún obligatoria para las partes o ha sido anulada o suspendida por una autoridad competente del país en que, o conforme a cuya ley, ha sido dictada esa sentencia." Esta causal tiene dos partes importantes: (i) laudo aún no obligatorio; y, (ii) laudo anulado. A continuación, se abordará la jurisprudencia relevante.

\subsubsection{Laudo aún no obligatorio}

Esta causal ha sido recurrentemente invocada y ha sido objeto de pronunciamiento en los casos de reconocimiento planteados ante las cortes latinoamericanas. Destacan: (a) Energía Eólica vs. Montealto Perú y Vestas Perú; (b) Mandate Holdings LLC vs. Consorcio Europa; (c) Qisheng Resources Limited vs. Minera Santa Fe; (d) Kreditanstalt fur Wiederaufbau vs. Inversiones Errazuriz Limitada; y, (e) Great Harvest vs. Shougang Corporation.

\subsubsection{Energía Eólica vs. Montealto Perú y Vestas Perú} En este caso, Montealto Perú S.A.C. (En adelante, "Montealto Perú") y Vestas Perú S.A.C. (En adelante, "Vestas Perú") celebraron un contrato, el cual remitía las futuras controversias a un arbitraje administrado de conformidad con las Reglas de la Cámara de Comercio Internacional.

Suscitada una serie de controversias entre las partes, las dos partes iniciaron un arbitraje contra la otra y pretendieron la incorporación de partes no signatarias.

En particular, Vestas Perú inició un arbitraje contra Montealto Perú, pero además solicitó la incorporación de Montealto XXI y Eoltec. Por su parte, Montealto Perú inició un arbitraje contra Vestas Perú, pero además solicitó la incorporación de Montealto XXI, Eoltec, Vestas Dinamarca, Vestas España y Energía Eólica S.A. (En adelante, "Energía Eólica").

Esos procedimientos arbitrales fueron consolidados en uno solo. Tanto Vestas Perú como Montealto Perú buscaban extender el convenio arbitral a diversas partes no signatarias. Sin embargo, estas últimas se opusieron y solicitaron que la parte que había solicitado su incorporación asuma los costos y gastos de su defensa.

En el caso particular de Energía Eólica, esta se opuso a la incorporación solicitada por Montealto Perú y solicitó además que esta última asuma los costos y gastos de representación incurridos con ocasión del arbitraje.

El 5 de junio de 2015 en París, el tribunal arbitral emitió Laudo Parcial sobre Jurisdicción, en el que resolvió, entre otras cuestiones, rechazar el pedido formulado por Montealto Perú para que Energía Eólica sea parte del arbitraje y la excluyó del mismo. Adicionalmente, ordenó a Montealto Perú pagar a Energía Eólica la suma de 150 mil euros por concepto de costos y gastos arbitrales, más los intereses desde la fecha de notificación del laudo hasta que se realice el pago a una tasa Euribor a 6 meses más dos puntos porcentuales (interés compuesto anual).

Energía Eólica solicitó el reconocimiento del laudo parcial de jurisdicción ante el Poder Judicial Peruano en el extremo relativo a la exclusión del arbitraje, así como la condena de costos a su favor.

Las partes demandadas fueron la condenada al pago, es decir, Montealto Perú y la otra parte del convenio arbitral, Vestas Perú. Montealto 


\section{Aplicación de la Convención de Nueva York por las cortes Lationamericanas Application of New York Convention by Latin American courts}

Perú no se apersonó al arbitraje, siendo declarada rebelde. Por su parte, Vestas Perú contestó la demanda de reconocimiento y solicitó que se reconozca el laudo parcial de jurisdicción, estando de acuerdo con lo planteado por Energía Eólica.

A través de una sentencia emitida el 19 de octubre de 2016, la Corte Superior de Justicia de Lima reconoció el laudo parcial de jurisdicción en los extremos solicitados.

La Corte analizó lo que denominó un requisito de procedibilidad y que consiste en que se presente un laudo extranjero. Sin embargo, parece que la real preocupación de la corte era evaluar si el laudo era obligatorio.

La Corte correctamente mencionó que la Convención de Nueva York no define qué se considera como laudo. Refirió que ese es un tema de suma relevancia para resolver el pedido de Energía Eólica:

"porque se solicita el reconocimiento del pronunciamiento de un tribunal arbitral que no pone fin al arbitraje ni resuelve el fondo de la controversia sometida a sede arbitral, sino que se limita a resolver negativamente los pedidos de inclusión al arbitraje de terceros (entre ellos, ENERGÍA EÓLICA) como pretendidas partes no signatarias, y condenar a una de las partes arbitrales al pago de costos y gastos arbitrales a favor de la recurrente" (CSJL 2016b).

En primer lugar, la Corte consideró que la calificación que dieron los árbitros al pronunciamiento no necesariamente determina si es un laudo para efectos del reconocimiento y que deba ser aceptado en todos los $\operatorname{casos}^{(20)}$.

La Corte también rechazó el criterio que solo son laudos finales aquellos que "materialmente ponen fin al proceso arbitral resolviendo como 'laudo final' la controversia sometida a decisión de los árbitros" (CSJL 2016b). Por ello, la Corte explicó que:

"(E)| vocablo "laudo" no ha de ser identificado necesariamente con "laudo final", esto es, el que resuelve la controversia de fondo entre las partes, por la razón acotada, de la existencia de pronunciamientos arbitrales calificados de "laudos finales" y "laudos parciales", además de otros pronunciamientos arbitrales, cuya existencia queda corroborada tanto por el Reglamento que rigió el arbitraje que nos ocupa como por la ley peruana (lex fori en el presente caso)" (CSJL 2016b).

En base a lo anterior, la Corte explicó que laudo es toda decisión que:

"con carácter final y definitivo con relación a aquellas cuestiones específicas que resuelve; independientemente del momento en que se emita (en el curso del arbitraje o en el momento postrero del mismo) y de su contenido: que resuelva el fondo de la controversia poniendo fin a la disputa y a la jurisdicción de los árbitros (laudo "final" strictu sensu), resuelva parte de la misma (propiamente, "laudo parcial" según el artículo 54 de la ley nacional), o resuelva cuestiones preliminares "que impidan entrar en el fondo de la controversia" (artículo 41 de la ley arbitral peruana), incluso si dicho pronunciamiento

(20) Véase Segunda Sala Civil con Subespecialidad Comercial de la Corte Superior de Justicia de Lima, Energía Eólica S.A. v. Montealto Perú S.A.C. y Vestas Perú S.A.C., Resolución 12, 19 de octubre de 2016, 15: "En primer lugar cabe advertir que el pronunciamiento cuyo reconocimiento se solicita, es denominado por el tribunal arbitral como "Laudo sobre Jurisdicción", lo que prima facie podría asumirse como suficiente para reconocerle la calidad de tal. Sin embargo, el Colegiado en consonancia con el principio que en Derecho las cosas son lo que son y no lo que se les denomine, recoge el estándar afirmado por la doctrina y jurisprudencia internacionales, que informa que es el contenido del laudo y no su designación lo que determina su naturaleza. Por tanto, el Colegiado adhiere al criterio que "la calificación de una decisión como laudo no depende de los términos utilizados por los árbitros o las partes", ya que ello importaría un "formalismo extremo e insostenible"; debiendo entenderse que una vez dictado el laudo, su calificación como tal deja de ser una prerrogativa de los árbitros y se inserta dentro de las facultades del órgano judicial a cuyo conocimiento sea sometido con fines de anulación, reconocimiento o ejecución". 


\section{Fernando Cantuarias Salaverry y Jose Luis Repetto Deville}

recae sobre alguna controversia incidental derivada del propio arbitraje (es decir, no aquella que origina el arbitraje propiamente dicho), como sería el caso, por ejemplo, de una excepción o cuestión previa" (CSJL 2016b).

Sin embargo, la Corte acotó que el laudo, además de ser definitivo o final, debe haber adquirido firmeza en la sede del arbitraje, lo cual está asociado al concepto de cosa juzgada. Ello, según los jueces se determina conforme al derecho de la sede del arbitraje.

Delimitado qué se entiende por laudo, la Corte apreció que bajo el derecho arbitral francés (lugar del arbitraje) el laudo es cosa juzgada respecto de las disputas resueltas en dicho laudo. La Corte apuntó que según dicho laudo la validez de la extensión del convenio arbitral está sujeta a la revisión de los tribunales franceses y que dicha revisión es un hecho que le compete ser invocado a la parte que se opone al reconocimiento, cuestión que no ha sido alegada ni probada.

Por último, la Corte concluyó correctamente que:

"(...) en el caso concreto que el pronunciamiento cuyo reconocimiento se solicita, contiene un extremo de condena de costos arbitrales a una de las emplazadas, que es un pronunciamiento perfectamente pasible de ejecución en sede peruana, como lo evidencia la abundante casuística en materia de ejecución de laudos, lo que coincide con jurisprudencia internacional que admite la ejecución de pronunciamientos arbitrales de condena de costos, independientemente que se les reconozca la calidad de laudo interino, laudo final o laudo parcial” (CSJL 2016b).

\subsubsection{Great Harvest International Investment vs. Shougang Corporation}

En este caso de reconocimiento ante las cortes peruanas, Great Harvest International Investment (En adelante, "Great Harvest") y Shougang Corporation (En adelante, "Shougang") celebraron un contrato denominado acuerdo de principios, en el que regularon una serie de derechos y obligaciones relacionados a ciertos activos. El contrato contenía una cláusula arbitral que remitía las futuras controversias a un arbitraje administrado de conformidad con las reglas del Comité de Arbitraje de Economía y Comercio Internacional de China, también conocido como CIETAC.
Resulta que, suscitada una controversia, Great Harvest inició un arbitraje ante el CIETAC contra Shougang. A través de un laudo arbitral dictado en China el 2 de marzo de 2011, el tribunal arbitral declaró que el acuerdo de principios tenía efectos legales, aunque todas las demás pretensiones del demandante fueron declaradas infundadas.

Great Harvest solicitó el reconocimiento del laudo ante el Poder Judicial Peruano. Ante ello, Shougang solicitó que se rechace el reconocimiento sobre la base del artículo V(1)(e) de la Convención de Nueva York y el artículo 75(2)(e) de la Ley de Arbitraje peruana. La parte demandada sostuvo que el laudo no podía ser obligatorio al ser meramente declarativo y no establecer obligaciones respecto a los derechos y obligaciones de las partes creadas en virtud del acuerdo de principios.

La Corte Superior de Justicia de Lima reconoció el laudo, porque consideró que el mismo sí era obligatorio. Sobre la base de doctrina especializada en la materia, la Corte explicó que el término obligatorio está referido a que el laudo no es susceptible de apelación ante una segunda instancia arbitral y que goza de la calidad de cosa juzgada.

Por ello, a juicio de la Corte un "laudo aún no es obligatorio cuando aún no ha quedado firme" (CSJL 2014). Adicionalmente, la Corte explicó que el propio laudo dispone en su parte resolutiva que es final y entra en vigencia desde el momento de su expedición (CSJL 2014). Por todo ello, la Corte consideró que el laudo sí era de obligatorio cumplimiento para las partes y que no cabía una apelación sobre el fondo.

3.5.1.3. Mandate Holdings LLC vs. Consorcio Europa

En este caso descrito anteriormente, otra de las razones argumentadas por Consorcio 


\section{Aplicación de la Convención de Nueva York por las cortes Lationamericanas Application of New York Convention by Latin American courts}

Europa para que se deniegue el reconocimiento, fue que el laudo no era obligatorio porque no había sido confirmado por las cortes de California (lugar del arbitraje).

La Corte Superior de Justicia de Brasil rechazó este planteamiento porque correctamente apreció que el laudo es final y vinculante en el momento en que se emite (SCJB 2013).

\subsubsection{Qisheng Resources Limited vs. Minera Santa Fe} En este caso también descrito antes, Minera Santa Fe se opuso al reconocimiento del laudo porque según expresó estaba pendiente de resolverse el recurso de anulación ante las cortes del lugar del arbitraje. La Corte Suprema de Chile rechazó el planteamiento de la parte demandada porque consideró que el laudo era obligatorio. En particular, la corte indicó que las Reglas de Arbitraje de la $\mathrm{CCl}$ disponen que las partes renunciaban a cualquier recurso que la legislación lo permita y, por tanto, las partes habían renunciado a recurrir el laudo en la sede de arbitraje. En adición a ello, la Corte Suprema de Chile indicó que el laudo también se convierte en obligatorio cuando lo confirman las cortes (SCJ of Chile 2016).

Aunque el resultado al cual llega la Corte Suprema de Chile es correcto, el razonamiento de considerar que el laudo es vinculante al momento en que es confirmado por el Poder Judicial de la sede del arbitraje no tiene fundamento. Como es bien sabido, la Convención de Nueva York abolió el sistema del doble-exequátur previsto en la Convención de Ginebra que requería que el laudo sea ejecutado en la sede del arbitraje para que luego pueda ser reconocido en otra jurisdicción. Como explica el Profesor Pieter Sanders, autor de la Convención de Nueva York:

"The main elements of the "Dutch proposal" were, first of all, the elimination of the double exequatur, one in the country where the award was made and another one in the country of the enforcement of the award. Under the Geneva Convention we always requested both. It is logical to require an exequatur only in the country where enforcement of the award is sought and not in the country where the award is made but no enforcement is sought. I remember that the disappearance of the double exequatur was so warmly welcomed during the Conference that the suggestion was made to create a new cocktail: the 'double exequatur'" (Sanders 1999, 12).
En el mismo sentido, una corte holandesa ha expresado que:

"An important improvement of the New York Convention in comparison with the Geneva Convention (...) is the fact that the double exequatur (leave for enforcement) is abolished. Under the Geneva Convention of 1927 , the double exequatur is indispensable because of the requirement that proof be given that means of recourse are no longer available against the award (Art. 1(2) (d)). This requirement is abolished by the New York Convention. Hence, it is no longer necessary to obtain an exequatur in the country where the award was made, before recognition and enforcement in another country can be sought. This new system is based on the idea that the requirement of an exequatur in the country of rendition entails unnecessary formalities and costs when the enforcement is not sought in that country but in another"(DCTH 1973).

3.5.1.5. Kreditanstalt fur Wiederaufbau vs. Inversiones Errazuriz Limitada (Chile)

En este caso, Kreditanstalt fur Wiederaufbau (En adelante, "KW") e Inversiones Errazuriz Limitada (En adelante, "Inverraz") celebraron un Basis Contract for the Concession of Individual Loans and a Loan Credit en virtud del cual, KW prestó determinadas sumas de dinero a Inverraz. Los contratos se encontraban regidos bajo el derecho alemán y establecían que todas las disputas serían resueltas mediante un arbitraje administrado por la ICC.

Cuando se generó una disputa debido a la falta de pago de Inverraz, KW inició un arbitraje ante la ICC. Los árbitros emitieron un laudo favorable de KW.

$\mathrm{KW}$ solicitó el reconocimiento del laudo ante las Cortes chilenas. Inverraz invocó diversas causales para que se deniegue el 


\section{Fernando Cantuarias Salaverry y Jose Luis Repetto Deville}

reconocimiento. En cuanto a lo que atañe a la causal bajo comentario, Inverraz sostuvo que el laudo no era vinculante o estaba suspendido, porque se encontraba pendiente que las cortes francesas resuelvan el recurso de anulación que había sido planteado. La Corte Suprema de Chile rechazó este argumento, porque consideró que el simple pedido de anulación no suspende los efectos del laudo bajo la Ley de Arbitraje de Chile de idéntico sentido que Ley Modelo UNCITRAL, que es a su vez, similar que la Convención de Nueva York ${ }^{(21)}$.

Como correctamente apuntó la corte, el pedido de anulación no suspende los efectos del laudo. El laudo debe ser efectivamente suspendido para que sea causal que anulación de laudo, lo cual en el caso bajo comentario no había sucedido.

\subsubsection{Laudo anulado en la sede}

Al menos en dos oportunidades, las cortes latinoamericanas se han enfrentado al pedido de reconocer un laudo que fue previamente anulado en la sede del arbitraje. $Y$ en esas dos oportunidades se trató de un mismo laudo que fue anulado. Se trata del caso entre EDF c. Endesa.

EDF Internacional SA (En adelante, "EDFI") celebró un contrato con Endesa Internacional (En adelante, "Endesa") y Astra Compañía de Petróleo S.A. (que luego se fusionó con YPF S.A. [En adelante, "YPF"]). El Contrato estaba relacionado con la compra de las acciones que Endesa e YPF tenían en dos compañías eléctricas argentinas. Dicho contrato remitía las futuras controversias a un arbitraje administrado por la ICC con sede en Buenos Aires.
EDFI inició un arbitraje contra Endesa e YPF por una controversia derivada del ajuste del precio de compra debido al tipo de cambio del peso a dólar.

El tribunal arbitral emitió un laudo en el cual acogió parte de los reclamos de EDFI. Adicionalmente, el tribunal arbitral concedió parte de los reclamos de Endesa e YPF.

Como consecuencia de lo decidido en el laudo, todas las partes solicitaron su anulación ante las cortes argentinas. La Cámara Nacional de Apelaciones de Buenos Aires declaró nulo el laudo, siendo la decisión confirmada por la Corte Suprema de Justicia de la Nación.

EDFI solicitó el reconocimiento del laudo ante las cortes chilenas y brasileñas. Sin embargo, no tuvo éxito en ninguna de ellas.

En el proceso de reconocimiento en Chile, Endesa se opuso al reconocimiento sobre la base que el laudo había sido anulado. La Corte Suprema de Chile se negó a reconocer el laudo en aplicación de la causal V(1)(E) de la Convención de Nueva York. En particular, la Corte Suprema de Chile afirmó:

(21) Véase Kreditanstalt für Wiederaufbau vs. Inversiones Errázuriz Limitada, Supreme Court of Justice of Chile, No. 5.2282008, December 15, 2009. En Albert Jan van den Berg ed., Yearbook Commercial Arbitration 2016, Vol. XLI, (Kluwer Law International, 2016), 38-40: “'Art. 36(1)(a)(v) of Law no. 19.971] reproduces 'almost' literally the provision of Art. V(1)(e) of the New York Convention; the difference is that Law no. 19.971 requires that the award be suspended by a judicial authority [only] of the country in which it was rendered. As noted by the Office of the Public Prosecutor, the sole fact that Inverraz filed an annulment appeal subsequent to the request for exequatur, without it being proved in this action that the Paris Court of Appeal held that the award is suspended, does not suffice to satisfy the requirement of our legislation on this point, because such a decision does not exist or has not been proved in this proceeding.

The fact that the mere filing of the annulment action in Paris has suspensive effects in French law or that in German law an exequatur issued by an ordinary German court is a prerequisite [for enforcement] is irrelevant, since the recognition of the award in Chile is sought, in accordance with the laws of Chile, in the present proceeding.

(...) It follows from this provision that in the system of the [ICC Rules] the award rendered by tribunal may not be modified, so that the appeal filed before the courts of France does not suspend its effects; the award maintains its efficacy and it is possible to enforce it as long as there is no contrary decision, since the [ICC arbitration] took place on the basis of an international contract concluded between a German bank and a Chilean borrower, which submitted to an arbitral body and not to the French judicial system." 


\section{Aplicación de la Convención de Nueva York por las cortes Lationamericanas Application of New York Convention by Latin American courts}

\begin{abstract}
"Que, establecida (...) la condición de nulo que ostenta el Laudo arbitral de que se trata, ha de tenerse con ello por configurada, de acuerdo con lo que se previene en la normativa que se acaba de examinar, una causal específica prevista en ella para la denegación de fuerza obligatoria a dicho fallo en nuestro país, en razón de no cumplir con el presupuesto de eficacia a que alude el art. 246 del Código de Procedimiento Civil. Que, establecida... la condición de nulo que ostenta el Laudo arbitral de que se trata, ha de tenerse con ello por configurada, de acuerdo con lo que se previene en la normativa que se acaba de examinar, una causal específica prevista en ella para la denegación de fuerza obligatoria a dicho fallo en nuestro país, en razón de no cumplir con el presupuesto de eficacia a que alude el art. 246 del Código de Procedimiento Civil" (SCJ of Chile 2011).
\end{abstract}

Adicionalmente, la Corte Suprema de Chile hizo notar la inconsistencia del planteamiento de EDFI, quien solicitó el reconocimiento de un laudo a pesar de había solicitado y obtenido su anulación ante el Poder Judicial Argentino:

"Que en el curso de estas disquisiciones, no pueden pasar por desapercibidos a estos sentenciadores ciertas situaciones relevantes que se evidencian en el proceso, estando constituida una de ellas por la circunstancia de haber EDFI instado ante los tribunales ordinarios superiores de la República Argentina por la nulidad del fallo; resultando, por lo tanto, carente de coherencia que, una vez declarada dicha nulidad, pretenda que se le reconozca en Chile fuerza obligatoria a esa misma sentencia que, a causa de la nulidad, ha quedado desprovista de eficacia jurídica en el propio país donde fue pronunciada.

Una situación como la descrita repugna al principio de los actos propios, con amplia consagración en la doctrina y la jurisprudencia, según el cual, no es lícito a una persona hacer valer un derecho en contradicción con un comportamiento desplegado por ella misma con anterioridad (venire contra factum proprium non potest); imponiéndose de esta manera en derecho al deber de respeto y sometimiento a una situación jurídica creada por su conducta pretérita" (SCJ of Chile 2011).

A pesar de que el laudo fue anulado en Argentina y que el Poder Judicial chileno había decidido denegar su reconocimiento, EDFI también solicitó el reconocimiento ante el Poder
Judicial brasileño. Endesa nuevamente invocó la causal $V(1)(e)$ para que se deniegue el reconocimiento. La Corte Superior de Justicia de Brasil denegó el reconocimiento del laudo, porque había sido anulado en la sede del arbitraje. Esta corte estableció que:

"(h)ence, since the arbitral award is null in Argentina because of the court decision issued there, its recognition in Brazil is not possible" (SCJB 2015).

Como se puede apreciar de la revisión de las decisiones reportadas, dos cortes de la región se negaron a reconocer un mismo laudo aplicando la causal $\mathrm{V}(1)(\mathrm{E})$ de la Convención de Nueva York. Aunque no es la oportunidad de pronunciarnos respecto al problema complejo que importa el reconocimiento de laudos anulados, dos países latinoamericanos no han abierto la puerta a la posibilidad de reconocer un laudo anulado en la sede del arbitraje.

\subsection{Causal V(2)(A): Materia No Arbitrable} De acuerdo con el artículo $\mathrm{V}(2)(\mathrm{A})$ de la Convención de Nueva York, se podrá denegar el reconocimiento de un laudo extranjero si "según la ley de ese país, el objeto de la diferencia no es susceptible de solución por vía de arbitraje". Existen al menos tres pronunciamientos de cortes latinoamericanas sobre este particular: (i) Stemcor UK Limited vs. Guiceve S.A.C.; (ii) Energía Eólica S.A. vs. Montealto Perú S.A.C. y Vestas Perú S.A.C.; $y$, (iii) Kreditanstalt fur Wiederaufbau vs. Inversiones Errazuriz Limitada. A continuación, abordaremos cada caso.

3.6.1. Stemcor UK Limited vs. Guiceve S.A.C. En este caso, la Corte Superior de Justicia de Lima se aproximó hacia una definición de materia no arbitrable. Los orígenes de la controversia entre Guiceve S.A.C. (En adelante, "Guiceve") y Stemcor UK Limited (En adelante, "Stemcor") se remontan a 


\section{Fernando Cantuarias Salaverry y Jose Luis Repetto Deville}

un contrato de compraventa internacional de mercaderías suscrito entre Stemcor en calidad de vendedor y Guiceve como comprador. Este contrato contenía una cláusula arbitral que remitía las controversias a un arbitraje administrado bajo los auspicios de la London Court of International Arbitration.

Luego de suscitada una controversia entre las partes, Guiceve inició un arbitraje ante la mencionada institución arbitral. Sin embargo, no presentó su demanda arbitral a tiempo.

Ante ello, el 21 de julio de 2010, el árbitro único que conoció la controversia, el reconocido profesor Nigel Blackaby, emitió un laudo en el que ordenó a Guiceve pagar a Stemcor 80,000 libras esterlinas por los costos legales razonables incurridos. Adicionalmente, el laudo ordenó a Guiceve asumir los costos del arbitraje. El laudo fue expedido en Londres.

Stemcor solicitó el reconocimiento ante el Poder Judicial peruano. En este procedimiento, Guiceve no se apersonó pese a haber sido notificado.

La Corte indicó que al no haberse formulado oposición al amparo de las causales previstas en la Convención de Nueva York y la Ley de Arbitraje, correspondía analizar las causales de oficio.

La Corte Superior de Justicia de Lima señaló que el objeto de la controversia resulta susceptible de ser sometido a arbitraje, toda vez que "al ser la controversia resuelta por el tribunal arbitral una que deriva de las relaciones comerciales entabladas entre Stemcor Uk Limited y Guiceve S.A.C. en mérito de un contrato privado de compra venta, es evidente que la materia sobre la cual se laudo es de derecho privado y por ende de libre disponibilidad, tanto más si el objeto de controversia no se encuentra dentro de la causa de excepción reguladas en el invocado artículo 2 de la Ley de Arbitraje" (CSJL 2011).

La Corte Superior apuntó correctamente que la arbitrabilidad debe interpretarse de manera restrictiva y, en caso de duda, debe preferirse que la controversia sea arbitrable (CSJL 2011). Creemos que la decisión es correcta.

3.6.2. Energía Eólica S.A. vs. Montealto Perú S.A.C. y Vestas Perú S.A.C.

En este caso descrito anteriormente, la Corte Superior de Justicia de Lima evaluó de oficio la arbitrabilidad de la disputa que se pretendía reconocer en el Perú. La Corte identificó correctamente que la arbitrabilidad tiene dos aspectos: El primero está relacionado con el carácter disponible de los derechos, siendo irrelevante si son contractuales o el contenido patrimonial de los mismos. El segundo no está vinculado a la naturaleza de los derechos, sino a que la ley define qué materia es susceptible de ser sometida a arbitraje ${ }^{(22)}$.

En tal sentido, la Corte apreció correctamente que la materia sometida a arbitraje era susceptible de ser sometida a arbitraje, ya que "si bien no recae o se pronuncia sobre dichas disputas de fondo, sin embargo define los alcances subjetivos del convenio arbitral, pronunciándose en forma negativa y definitiva sobre los pedidos cruzados de incorporación al arbitraje de terceros en calidad de partes no signatarias" (CSJL 2016b).

(22) Véase Segunda Sala Civil con Subespecialidad Comercial de la Corte Superior de Justicia de Lima, Energía Eólica S.A. vs. Montealto Perú S.A.C. y Vestas Perú S.A.C., Resolución 12, 19 de octubre de 2016, 28: "Otro aspecto que define la arbitrabilidad de una materia es aquél que no presta atención a la naturaleza de los derechos implicados, sino que se remite a la ley, que definirá que una materia es susceptible de ser sometida a arbitraje, caso en el que la arbitrabilidad no se sustenta en la autonomía de la voluntad de los sujetos sino en el voluntarismo estatal que opta, por razones de índole diversa, por permitir -u obligar, de ser el caso- que determinados asuntos sean resueltos mediante arbitraje. Actualmente es viable el arbitraje en materia laboral, de telecomunicaciones, hidrocarburos, protección al consumidor, bolsa de valores, bolsa de productos, banca y seguros, contrataciones con el Estado, salud, transporte, propiedad informal, expropiaciones (el aspecto de la indemnización), aeronáutica civil, saneamiento, medio ambiente, concursal, societario, entre otros, existiendo normatividad que lo dispone". 


\section{Aplicación de la Convención de Nueva York por las cortes Lationamericanas Application of New York Convention by Latin American courts}

\begin{abstract}
3.6.3. Kreditanstalt fur Wiederaufbau vs. Inversiones Errazuriz Limitada

Finalmente, en este caso también descrito anteriormente, Inverraz solicitó que se deniegue el reconocimiento del laudo, porque KW (la demandante) era una organización sin fines de lucro y de acuerdo con las leyes chilenas, dichas instituciones no pueden someter sus controversias a arbitraje. La Corte Suprema de Chile estableció que la norma invocada por Inverraz solamente regulaba a las organizaciones sin fines de lucro constituidas en Chile y que no abarcaba a KW, que era una organización incorporada en Alemania. En dicha oportunidad, la Corte Suprema indicó que:
\end{abstract}

"En cuanto a que en Chile el objeto de la diferencia no es susceptible de solución por vía de arbitraje. Esta alegación importaría la circunstancia a que hace referencia el apartado i) de la letra b) del $\mathrm{N}^{\circ}$ 1) del artículo 36 de la Ley 19.971, es decir, si el tribunal comprueba que según la ley chilena el objeto de la controversia no es susceptible de arbitraje.

Discurre el oponente que el banco KFW sería una corporación de derecho público sin fines de lucro que opera como banco de fomento, y por tal calidad las materias que afectan sus bienes no serían susceptibles de ser sometidas a arbitraje de acuerdo con los artículos 230 inciso segundo y $357 \mathrm{~N}^{\circ} 5$ del Código Orgánico de Tribunales, además formula las alegaciones destinadas a desconocer la jurisdicción y competencia arbitral.

Señala la fiscal judicial que las referencias que hacen las normas legales recién señaladas a las "corporaciones o fundaciones de derecho público" dicen relación con las entidades que tienen tal calidad de acuerdo con la legislación nacional, es decir, corporaciones o fundaciones chilenas y por tanto no pueden aplicarse extraterritorialmente, atribuyendo tal naturaleza a personas jurídicas extranjeras."

Consecuentemente, consideramos correcto que la corte haya realizado una lectura restrictiva de la arbitrabilidad.

\subsection{Causal V(1)(B): Violación del orden público internacional} De acuerdo con el artículo $\mathrm{V}(2)(\mathrm{B})$ de la Convención de Nueva York, se podrá denegar el reconocimiento de un laudo extranjero si "el reconocimiento o la ejecución de la sentencia serían contrarios al orden público de ese país.". Hemos identificado cuatro pronunciamientos de las cortes latinoamericanas sobre este particular: (i) Stemcor UK Limited v. Guiceve S.A.C.; (ii) Energía Eólica S.A. v. Montealto Perú S.A.C. y Vestas Perú S.A.C.; (iii) Keytrade AG v. Ferticitrus Industria e Comercio de Fertilizantes Ltda.; y, (iv) Petrotesting Colombia S.A. v. Ross Energy S.A. A continuación, analizaremos para uno de los casos.

3.7.1. Stemcor UK Limited vs. Guiceve S.A.C. En este caso descrito anteriormente, la Corte Superior de Justicia de Lima tuvo la oportunidad de pronunciarse respecto al orden público internacional y por qué el laudo no lo violaba.

Para tal efecto, la Corte definió al orden público como "el conjunto de principios e instituciones que se consideran fundamentales en la organización social de un país y que inspiran su ordenamiento jurídico" (CSJL 2011).

Acto seguido, la Corte consideró que el laudo había respetado los principios, derechos y garantías constitucionales y que el laudo se emitió siguiendo las normas imperativas (CSJL 2011).

3.7.2. Energía Eólica S.A. vs. Montealto Perú S.A.C. y Vestas Perú S.A.C.

En este caso descrito anteriormente, la Corte Superior de Justicia de Lima también se pronunció respecto a la causal de orden público internacional. Lo interesante es cómo se aproximó la Corte ante este importante concepto.

En primer lugar, la Corte apuntó correctamente que la Convención de Nueva York, a pesar de que menciona como causal de denegación de reconocimiento que el laudo sea contrario "al orden público del país en que se realiza dicho reconocimiento", se está refiriendo en realidad al orden público internacional (CSJL 2016b).

En cuanto a qué se considera por orden público internacional, la Corte identificó que se trata de: 


\section{Fernando Cantuarias Salaverry y Jose Luis Repetto Deville}

“(...) un concepto jurídico indeterminado cuyo contenido varía según el tiempo y el lugar, por lo que no tiene el mismo contenido hoy que antaño, ni es el mismo en todos los Estados; así, incluso se le ha simbolizado como un 'camaleón empedernido que constantemente cambia de apariencia'. Pero además de ser relativo, es una noción totalizante a la vez que gaseosa, difícil de precisar, que aparece relacionada con las reglas básicas establecidas para satisfacer intereses que hacen a la supervivencia de un país. Así, el orden público involucra aquellos principios que inspiran un ordenamiento jurídico determinado, reflejando los valores esenciales de una sociedad en un momento dado, en orden a lo cual la doctrina nacional indica que el orden público es el conjunto de "principios fundamentales y de interés general [...] sobre los que se apoya el ordenamiento jurídico de un determinado Estado" (CSJL 2016b).

En tal sentido, la Corte expresó que existen tres principios para dotar de contenido al orden público internacional: excepcionalidad o aplicación en circunstancias extraordinarias, interpretación restrictiva y nivel de revisión mínimo (CSJL 2016b).

3.7.3. Keytrade AG vs. Ferticitrus Industria e Comercio de Fertilizantes Ltda.

En este caso, la Corte Superior de Justicia de Brasil tuvo que responder si la aplicación de intereses compuestos ordenados en un laudo arbitral que se pretendía reconocer, violaba el orden público internacional brasileño. El origen de la controversia deriva del contrato de compraventa de nitrato de amoniaco, suscrito entre Keytrade AG (En adelante, "Keytrade") y Ferticitrus Industria e Comercio de Fertilizantes Ltda. (En adelante, "Ferticitrus"). La cláusula de resolución de disputas sometía las controversias a un arbitraje con sede en Londres.

Keytrade inició un arbitraje contra Ferticitrus derivado de alegadas demoras en la descarga de los fertilizantes. El laudo resultó favorable a Keytrade.

Keytrade solicitó el reconocimiento del laudo ante las cortes brasileñas. Ferticitrus se opuso al reconocimiento, argumentando que el laudo violaba el orden público internacional brasileño, porque había ordenado pagar los costos del arbitraje a una tasa de interés compuesto anual del
$8 \%$ por año. Según argumentó Ferticitrus, el sistema legal brasileño condenaba todas las formas de usura, incluyendo el cobro de tasas de interés compuesto como lo había dispuesto el laudo que se pretendía reconocer.

La Corte Superior de Brasil concluyó que el laudo no violaba el orden público brasileño, porque el Código Civil brasileño sí permitía convenir intereses compuestos en el caso de préstamos. En particular, la Corte Superior de Brasil indicó que:

"we must stress - despite the absolute prohibition of the capitalization of interest in the Brazilian legal system - that Art. 591 of the 2002 Civil Code, when dealing with loans with an economic aim between private persons, expressly allows for the stipulation of compound interest, so that this practice, like the various legal provisions limiting its periodicity or non-incidence (depending on the legal relationship), is not prohibited by Brazilian law. As a consequence, there is no violation of public policy" (STJB 2013).

Consideramos que el razonamiento de la Corte Superior de Justicia de Brasil es particularmente relevante. La corte aplicó correctamente el concepto de orden público y analizó si bajo su sistema legal dicha figura (tasas de interés compuesto) se encuentra permitida o no. Como se encuentra permitido el pacto de interés compuesto en Brasil, la corte correctamente estableció que dicha situación establecida en el laudo no puede generar una violación de su orden público internacional.

3.7.4. Petrotesting Colombia S.A. y otros vs. Ross Energy S.A. (Colombia)

A través de este caso, la Corte Suprema de Colombia tuvo la oportunidad de definir el concepto de orden público internacional aplicable al reconocimiento de laudos arbitrales extranjeros. 


\section{Aplicación de la Convención de Nueva York por las cortes Lationamericanas Application of New York Convention by Latin American courts}

Los antecedentes de esta controversia se remontan a la celebración de un acuerdo de consorcio entre Holsan Chemicals Ltda. (sucedida por "Ross Energy"), Petrotesting Colombia S.A. (En adelante, "Petrotesting") y Eico Ltda (sucedida por "Rosneft"), que creó la Sociedad Consorcio Colombia Energy (En adelante, "Consorcio") a fin de participar en una licitación de Ecopetrol para la exploración y explotación de un pozo petrolero en Colombia.

Como resultado de ganar la licitación, Petrotesting, Ross Energy y Rosneft celebraron un Joint Operating Agreement, bajo el cual regularon sus derechos y obligaciones en relación con el contrato entre el Consorcio y Ecopetrol. Este contrato refería las futuras disputas a un arbitraje administrado por la American Arbitration Association.

Posteriormente, los miembros del Consorcio celebraron un Operator Agreement que estableció a Petrotesting como operador y que tenía una cláusula arbitral idéntica a la contenida en el Joint Operating Agreement.

Petrotesting y Rosneft iniciaron un arbitraje contra Ross Energy ante la American Arbitration Association debido a incumplimientos de Ross Energy. El laudo emitido en dicho procedimiento fue favorable para los demandantes.

Petrotesting y Rosneft solicitaron el reconocimiento del laudo ante el Poder Judicial colombiano. Ross Energy se opuso al reconocimiento sobre la base de la causal $\mathrm{V}(2)(\mathrm{B})$. En específico, Ross Energy sostuvo que el laudo violaba el orden público internacional colombiano, toda vez que -según argumentó- bajo la Constitución de Colombia el Estado es el único propietario de los hidrocarburos y que los contratos de exploración y explotación de hidrocarburos deben regirse bajo el derecho colombiano y encontrarse sometidos a la competencia de las cortes colombianas. En ese sentido -según sostuvo Ross Energy- los árbitros resolvieron una controversia de competencia exclusiva del Poder Judicial violando así el orden público internacional colombiano.

Dicha argumentación llevó a la Corte Suprema de Colombia a discutir la noción del orden público internacional. En la sentencia de reconocimiento, la Corte Suprema de Colombia correctamente estableció que:

"el concepto de 'orden público' que en el foro nacional tiene la virtualidad de enervar el reconocimiento o la ejecución de un 'laudo extranjero', hecho bajo el amparo de la aludida Convención de Nueva York, se limita a los principios básicos o fundamentales de las instituciones, a lo cual servirían de ilustración: la prohibición del ejercicio abusivo de los derechos, la buena fe, la imparcialidad del tribunal arbitral y el respeto al debido proceso. Por lo tanto, en principio, el desconocimiento de una norma imperativa propia del 'foro' del juez del exequátur, per se, no conlleva un ataque al mencionado instituto, lo será, si ello trae como consecuencia el resquebrajamiento de garantías de linaje superior, como las antes enunciadas"(23).

Teniendo en cuenta la definición antes indicada, la Corte Suprema de Colombia consideró que el orden público colombiano no se ve afectado porque la controversia era entre partes privadas que surgía de un contrato entre privados que no es un contrato público y que los contratos celebrados entre las partes en controversia no se encuentran

(23) Véase Petrotesting Colombia S.A. y otros vs. Ross Energy S.A., Supreme Court of Justice of Colombia, July 27, 2011. En Albert Jan van den Berg ed., Yearbook Commercial Arbitration 2012, Vol. XXXVII, (Kluwer Law International, 2012), 40: "the notion of public policy which can prevent the recognition and enforcement of a foreign award under the said Convention in Colombia is limited to the basic or fundamental principles of the [Colombian] institutions, such as: prohibition of abuse of rights; good faith; impartiality of the arbitral tribunal and due process. Thus, in principle, non-compliance with a mandatory provision of the forum of the exequatur court does not per se violate public policy, though it will if it leads to a violation [of] higher-level guarantees such as those mentioned above." 


\section{Fernando Cantuarias Salaverry y Jose Luis Repetto Deville}

dentro del ámbito de aplicación de los contratos públicos de hidrocarburos que deben ser sometidos a la jurisdicción de las cortes colombianas. Consecuentemente, el análisis es correcto, así como la definición esbozada por la Corte Suprema de Colombia.

\section{Comentarios finales}

La Convención de Nueva York es, como se ha afirmado(24), el tratado más exitoso en la historia del derecho comercial. Este tratado representa una de las principales ventajas significativas que llevan a los contratantes internacionales a elegir el arbitraje en vez del Poder Judicial.

Por paradójico que parezca, para que este tratado funcione bien y sea un éxito depende en gran medida del Poder Judicial. Es al final de cuentas el Poder Judicial quien tiene la última palabra sobre si un laudo dictado en el extranjero va a tener efectos en su Estado. En simple, el Poder Judicial es el verdadero protagonista del éxito del arbitraje.

La Convención de Nueva York se redactó para hacer más fácil y sencillo el reconocimiento de laudos extranjeros, así como para establecer las máximas causales que puede utilizar un Estado para denegar el reconocimiento de un laudo. $Y$ de hecho que lo logró. Conservar el éxito depende de las cortes.

A lo largo de este artículo hemos podido comprobar que, en el Perú y, en general, en América Latina, la Convención de Nueva York se aplica correctamente, en cuanto al reconocimiento de laudos extranjeros.

Quizás esto no sea una buena noticia para aquellas partes que pierden arbitrajes en el extranjero y que tienen activos en América Latina. Es más bien una advertencia que dicho laudo será reconocido en América Latina y que más tarde que nunca tendrán que pasar por la ventanilla del vencedor del laudo a pagar.

\section{Referencias bibliográficas}

Albanesi, Christian. 2015. Advances in International Commercial Arbitration in Latin America during John's Presidency of the ICC Court. En International Arbitration Under Review: Essays in Honour of John Beechey, eds. Andrea Carlevaris, Laurent Lévy, Alexis Mourre, Eric A. Schwartz. International Chamber of Commerce.

Asamblea Legislativa de la República. 2011. Ley 8937. Costa Rica: Asamblea Legislativa de la República.

Born, Gary. 2014. International Commercial Arbitration. $2^{a}$ ed. Kluwer Law International.

Congreso de la República. 2012. Ley 1563. Colombia: Congreso de la República.

Congreso de la República. 2008. Decreto Legislativo 1071. Perú: Congreso de la República.

Congreso de los Estados Unidos Mexicanos. 1993. Decreto del 22 de julio de 1993. México: Congreso de los Estados Unidos Mexicanos.

Congreso Nacional. 2004. Ley 19971. Chile: Congreso Nacional.

Congreso Nacional. 2008. Ley 489-08. República Dominicana: Congreso Nacional.

Comisión de las Naciones Unidas para el Derecho Mercantil Internacional. 1958.

(24) Véase Michael Lord Mustill, "Arbitration: History and Background”. En Journal of International Arbitration, Vol. 6, No. 2, 1989, 49: "(T)his Convention has been the most successful international instrument in the field of arbitration, and perhaps could lay claim to be the most effective instance of international legislation in the entire history of commercial law". 


\section{Aplicación de la Convención de Nueva York por las cortes Lationamericanas Application of New York Convention by Latin American courts}

Convención sobre el Reconocimiento y la Ejecución de las Sentencias Arbitrales Extranjeras (Convención de Nueva York). Nueva York: Comisión de las Naciones Unidas para el Derecho Mercantil Internacional.

Corte Superior de Justicia de Lima. 28 de abril de 2011. Primera Sala Civil con Subespecialidad Comercial. Resolución 8. Stemcor UK Limited vs. Guiceve S.A.C.

9 de enero de 2013a. Primera Sala Civil con Subespecialidad Comercial. Resolución 5. Ji Ye International Limited vs. Pesquera Natalia S.A.C.

2 de octubre de 2013b. Primera Sala Comercial. Gobierno Regional de Pasco vs. Consorcio Acruta Tapia Ingenieros S.A.C.

10 de diciembre de 2014. Primera Sala Civil con Subespecialidad Comercial. Resolución 54. Great Harvest International Investment vs. Shougang Corporation.

20 de enero de 2016a. Segunda Sala Civil con Subespecialidad Comercial. Resolución 13. Plains Cotton Cooperative Association vs. Corporación Textil S.A.

19 de octubre de 2016b. Segunda Sala Civil con Subespecialidad Comercial. Resolución 12. 19 de octubre. Energía Eólica S.A. vs. Montealto Perú S.A.C. y Vestas Perú S.A.C.

District Court of The Hague. 26 de abril de 1973. German (F.R.) party vs. Dutch party.

Gaceta Oficial. 2013. Ley 131. Panamá: Gaceta Oficial.

Grigera Naón, Horacio. 2007. Arbitration and Latin America: Progress and Setbacks. En Arbitration Insights: Twenty Years of the Annual Lecture of the School of International Arbitration, Vol. 16, eds. Loukas A. Misteils y Julian D. M. Lew, 393-454. Kluwer Law International. https://doi.org/10.1093/ arbitration/21.2.127

Lord Mustill, Michael. 1989. Arbitration: History and Background. Journal of International Arbitration 2:43-56.

Sanders, Pieter. 1999. The History of the New York Convention. En Improving the Efficiency of Arbitration Agreements and Awards: 40
Years of Application of the New York Convention. Vol. 9, ICCA Congress Series, ed. Albert Jan van den Berg. Kluwer Law International.

Supreme Court of Justice of Argentina. 24 de mayo de 2011. Armada Holland BV vs. Inter Fruit S.A. En Yearbook Commercial Arbitration 2014 - Volume XXXIX, ed. Albert Jan van den Berg. Kluwer Law International, 2014.

Superior Court of Justice of Brazil. 6 de febrero 2013. Mandate Holdings LLC vs. Consórcio Europa. SEC No. 6.365 - EX (2011/01005990). En Yearbook Commercial Arbitration 2013 - Volume XLI, ed. Albert Jan van den Berg. Kluwer Law International, 2013.

2 de diciembre de 2015. EDF International S/A vs. Endesa Latinoamérica S/A. SEC No. 5.782 - EX. En Yearbook Commercial Arbitration 2016 - Volume XL1, ed. Albert Jan van den Berg. Kluwer Law International, 2016.

Supreme Court of Justice of Chile. 8 de setiembre 2009a. Comverse Inc. vs. American Telecommunication, Inc. En Yearbook Commercial Arbitration 2016 - Volume XLI, ed. Albert Jan van den Berg. Kluwer Law International, 2016.

15 de diciembre de 2009b. Kreditanstalt für Wiederaufbau vs. Inversiones Errázuriz Limitada. No. 5.228-2008. En Yearbook Commercial Arbitration 2016 - Volume XLI, ed. Albert Jan van den Berg. Kluwer Law International, 2016.

8 de setiembre de 2011. EDF Internacional S/A vs. Endesa Latinoamericana S/A. No. 4.390-2010. En Yearbook Commercial Arbitration 2016 - Volume XLI, ed. Albert Jan van den Berg. Kluwer Law International, 2016.

21 de abril de 2016. Qisheng Resources Limited vs. Minera Santa Fe. En Yearbook 


\section{Fernando Cantuarias Salaverry y Jose Luis Repetto Deville}

Commercial Arbitration 2016 - Volume XLI, ed. Albert Jan van den Berg. Kluwer Law International, 2016.

Supreme Court of Justice of Colombia. 27 de Julio de 2011. Petrotesting Colombia S.A. y otros vs. Ross Energy S.A. 11001-0203-0002007-01956-00. En Yearbook Commercial Arbitration 2012 - Volume XXXVII, ed. Albert Jan van den Berg. Kluwer Law International, 2012.

3 de mayo de 2012. Drummond Ltd. vs. Instituto Nacional de Concesiones - INCO y otros. En Yearbook Commercial Arbitration 2012 - Volume XXXVII, ed. Albert Jan van den Berg. Kluwer Law International, 2012.

7 de setiembre de 2016. Empresa de Generación Eléctrica del Sur S.A. - Egesur S.A. vs. Consorcio Pisco. En Yearbook Commercial Arbitration 2017 - Volume XLII, ed. Albert Jan van den Berg. Kluwer Law International, 2017.

Superior Tribunal de Justiça of Brazil. 7 de agosto de 2013. Keytrade AG vs. Ferticitrus
Indústria e Comércio de Fertilizantes Ltda. SEC No. 4042EX (2010/0073632-7). En Yearbook Commercial Arbitration 2014 - Volume XXXIX, ed. Albert Jan van den Berg. Kluwer Law International, 2014.

21 de mayo de 2014. CIMC Raffles Offshore Limited y otros vs. Schahin Holding SA y otros. SEC No. 9880 - EX (2013/0296479-3). En Yearbook Commercial Arbitration 2015 - Volume XL, ed. Albert Jan van den Berg. Kluwer Law International, 2015.

4 de marzo 2015a. Huawei do Brasil Telecomunicações Ltda vs. Zune Consultoria de Telecomunicações Ltda. SEC No. 8.242 - EX. En Yearbook Commercial Arbitration 2016 - Volume $X L I$, ed. Albert Jan van den Berg. Kluwer Law International, 2016.

16 de setiembre de 2015b. Mercovia S/A vs. Comissao Mista Argentino Brasileira. SEC No. 10-432 - EX. En Yearbook Commercial Arbitration 2016 - Volume XLI, ed. Albert Jan van den Berg. Kluwer Law International, 2016.

16 de diciembre de 2015c. Thyssenkrupp Steel Europe AG vs. Companhia Siderúrgica Nacional CSN. SEC No. 12.236-EX. En Yearbook Commercial Arbitration 2016 - Volume XLI, ed. Albert Jan van den Berg. Kluwer Law International, 2016. 